\title{
Performance of Mg-air Battery Based on AZ31 Mg Alloy Sheets with Different Grain Sizes
}

\author{
Yanchun Zhao ${ }^{1}$, Guangsheng Huang ${ }^{2,3, *}$, Cheng Zhang ${ }^{2}$, \\ Cheng Peng ${ }^{l}$ and Fusheng Pan ${ }^{2,3}$ \\ ${ }^{1}$ Chongqing Key Laboratory of Extraordinary Bond Engineering and Advanced Materials Technology, \\ Yangtze Normal University, Chongqing 408100, China \\ ${ }^{2}$ State Key Laboratory of Mechanical Transmission, Chongqing University, Chongqing 400044, China \\ ${ }^{3}$ National Engineering Research Center for Magnesium Alloys, Chongqing University, Chongqing \\ 400044, China \\ *E-mail: gshuang@cqu.edu.cn
}

doi: $10.20964 / 2018.09 .37$

Received: 24 April 2018 / Accepted: 7 June 2018 / Published: 5 August 2018

\begin{abstract}
$\mathrm{Mg}$-air batteries have attracted great attention recently because of their high energy density and lack of pollution. This paper studied the effect of grain sizes on the performance of Mg-air batteries. AZ31 Mg alloy sheets with different grain sizes were obtained through cold-rolling and annealing. The potentiodynamic polarization curves revealed that AZ31 Mg alloy sheets with fine grain sizes have higher electrochemical activity and better corrosion resistance compared to AZ31 Mg alloy sheets with coarse grain sizes. Mg-air batteries based on processed AZ31 alloy sheets were prepared, and the battery performances were investigated by a constant-current discharging test. The results show that the Mg-air battery based on a fine-grain anode exhibited a preferable discharge performance, including a higher discharge voltage and a higher anodic efficiency that those of the battery is a coarse-grain anode.
\end{abstract}

Keywords: Mg alloys, Grain size, Electrochemical property, Mg-air battery, Anodic efficiency, Discharge voltage

\section{FULL TEXT}

(C) 2018 The Authors. Published by ESG (www.electrochemsci.org). This article is an open access article distributed under the terms and conditions of the Creative Commons Attribution license (http://creativecommons.org/licenses/by/4.0/). 